\title{
VIRTUAL LIBRARIES OF TISSUE AND CLINICAL SAMPLES: POTENTIAL ROLE OF A 3-D MICROSCOPE
}

\author{
A. Peña-Fernández ${ }^{1}$, F. Izquierdo², L. Acosta ${ }^{3}$, M.A. Peña ${ }^{4}$, A. Magnet ${ }^{2}$, \\ M.D. Evans ${ }^{1}$, G. Torrado ${ }^{4}$, C. Young ${ }^{1}$ \\ ${ }^{1}$ De Montfort University, Faculty of Health and Life Sciences (UNITED KINGDOM) \\ ${ }^{2}$ Universidad San Pablo CEU, Facultad de Farmacia (SPAIN) \\ ${ }^{3}$ Universidad Miguel Hernández de Elche (SPAIN) \\ ${ }^{4}$ Universidad de Alcalá, Departamento de Ciencias Biomédicas (SPAIN)
}

\begin{abstract}
Our international innovative teaching group from different European Universities (De Montfort University, DMU, UK; and the Spanish University of Alcalá, University Miguel Hernández and University of San Pablo CEU), in conjunction with practicing biomedical scientists in the National Health Service (UK) and biomedical researchers, are developing two complete e-learning packages for teaching and learning medical parasitology, named DMU e-Parasitology (accessible at: http://parasitology.dmu.ac.uk), and biology and chemistry, named DMU e-Biology (accessible at: http://parasitology.dmu.ac.uk/ ebiology/index.htm), respectively. Both packages will include a virtual microscope with a complete library of digitised tissue images, clinical slides and cell culture slides/mini-videos for enhancing the teaching and learning of a myriad of techniques applicable to health science undergraduate and postgraduate students. Thus, these packages include detecting human parasites, by becoming familiar with their infective structures and/or organs (e.g. eggs, cysts) and/or explore pathogenic tissues stained with traditional (e.g. haematoxylin \& eosin) or more modern (e.g. immunohistochemistry) techniques. The Virtual Microscope (VM) module in the DMU e-Parasitology package is almost completed (accessible at: http://parasitology.dmu.ac.uk/learn/microscope.htm) and contains a section for the three major groups of human-pathogenic parasites (Peña-Fernández et al., 2018) [1]. Digitised slides are provided with the functionality of a microscope by using the gadget Zoomify ${ }^{\circledR}$, and we consider that they can enhance learning, as previous studies reported in the literature have reported similar sensitivity and specificity rates for identification of parasites for both digitised and real slides. The DMU e-Biology's VM, currently in development, will provide healthy and pathological tissue samples from a range of mammalian tissues and organs.
\end{abstract}

This communication will provide a description of both virtual libraries and the process of developing them. In conjunction, we will use a three-dimensional (3D) super-resolution microscopy, 3D Cell Explorer (Nanolive, Lausanne, Switzerland), to incorporate potential 3D microscopic photographs/short videos of cells to provide students with information about the spatial arrangement and morphologies of cells that are essential for life.

Keywords: DMU e-Parasitology, DMU e-Biology, virtual microscope, 3D microscope.

\section{INTRODUCTION}

Despite recent advances in biomedicine, the diagnosis of major and important parasitic diseases in most of the laboratories still relies on the morphological identification of the parasites or their infective forms using different microscopy techniques such as light or fluorescence microscopy [1]. However, this ability requires robust skills acquired through comprehensive and rigorous training [2]. Microscopy techniques are also critical for the study of histology and histopathology, however several limitation have been described recently by Čapo et al. (2017) [3], which include: high number of resources (e.g. numerous glass slides, particularly of human tissue samples, and microscopes), time and skilled personnel necessary to teach large groups of students currently enrolled in any human health science degree, including students' poor knowledge/lack of skills in using a microscope. However, the ability to identify human parasites or distinguish between healthy from pathogenic human tissue is of critical importance for different future health professionals, such as pharmacists, medical doctors, physician associates or biomedical/clinical scientists.

To facilitate the teaching of medical parasitology and histology, different EU Universities including De Montfort University (DMU, Leicester, UK) and the Spanish Universities of San Pablo CEU (USP-CEU, 
Madrid) and Miguel Hernández (Elche), in conjunction with practising Biomedical Scientists from the UK National Health Service are developing the following novel web-based packages:

- DMU e-Parasitology $\rightarrow$ complete on-line environment for the teaching and learning of major and rare parasitic diseases affecting humans. The package is publicly available on the DMU website (http://parasitology.dmu.ac.uk/ [4]) and is expected to be completed in 2019. The DMU eParasitology package will have four sections or modules (Fig. 1), with comprehensive and interactive up-to-date units that will provide a holistic learning of medical parasitology to the user. Sections are: a) a theoretical module with e-learning units on major and rare human parasites [5]; b) a virtual laboratory module with units related to techniques and equipment for detecting, identifying and studying parasitic diseases [6]; c) a virtual microscope module with a real slide collection of clinical samples of parasites [1]; and d) a virtual clinical case studies module to provide the user with some initial clinical skills to diagnose parasitic diseases and infections due to human parasites [7-8].

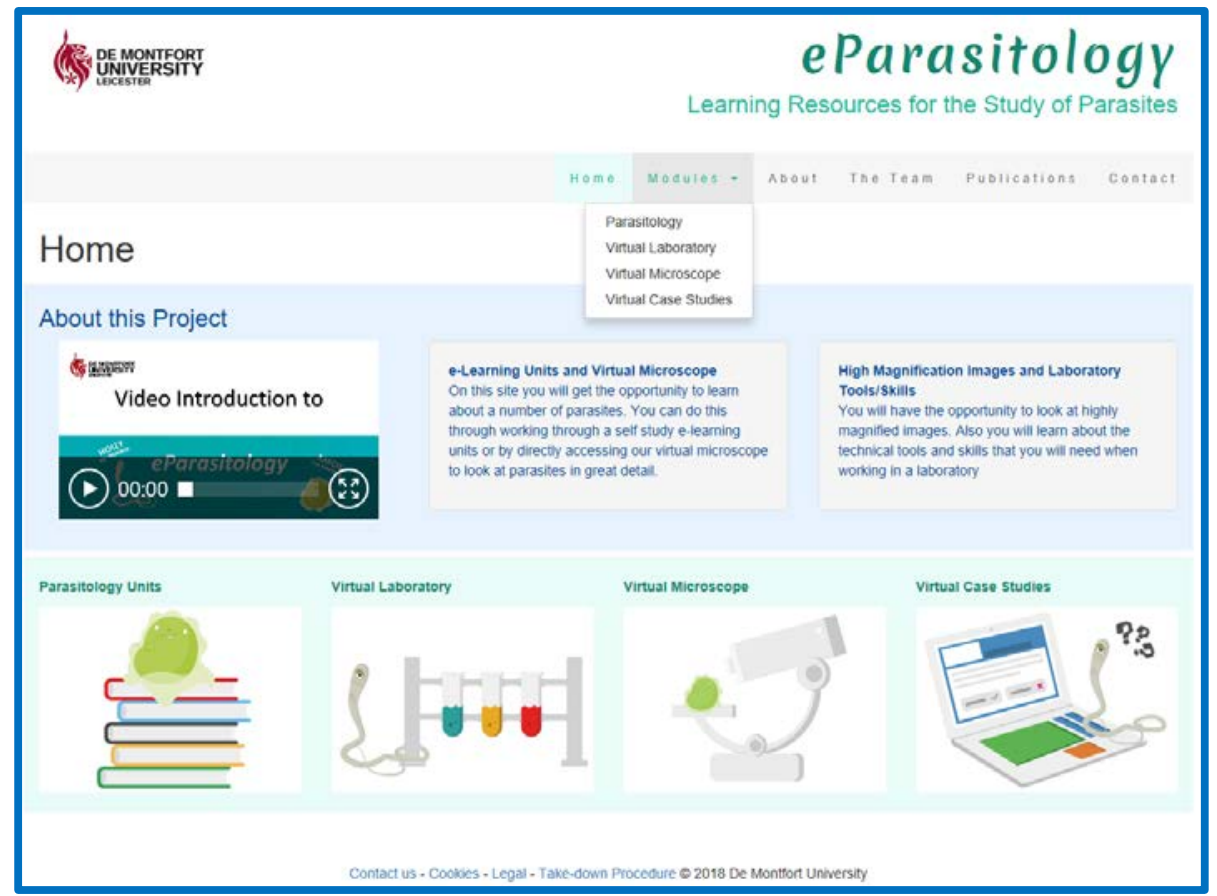

Figure 1. Overview of the DMU e-Parasitology showing the four sections or modules (Image courtesy of DMU; Peña-Fernández A. [4]) http://parasitology.dmu.ac.uk/index.htm

- DMU e-Biology $\rightarrow$ a complete e-learning package designed to enhance learning and underpin the fundamental concepts of biology and biochemistry. This e-learning package will cover the specifications for AS and A level described by the Assessment and Qualifications Alliance (AQA, 2017 [9]) for human biology as well as the basic concepts delivered in our first year modules; and will be publicly available at http://parasitology.dmu.ac.uk/ebiology/index.htm [10] in 2020/21, after completion of the specific units and resources. The DMU e-Biology package has the same sections/modules as the DMU e-Parasitology, which aim to provide the user with a holistic experience in the study and learning of general biology, basic chemistry and microbiology, cell and histology and biochemistry. A preliminary description of the future DMU e-Biology and the methods and resources that we are following for its development are described in PeñaFernández et al. (2017) [11]. The sections that are closest to completion are the theoretical module (Fig. 2), which includes the following subsections: a) brief introduction to biology; b) chemistry; c) cells; d) cellular respiration; e) tissues, anatomy and physiology; f) genetics and g) microbiology; and the histology section [12] in the DMU e-Biology virtual laboratory module. This novel web-based DMU environment will also be provided with a virtual microscope module with real clinical slides of human tissue samples for the study of human histology and histopathology. 


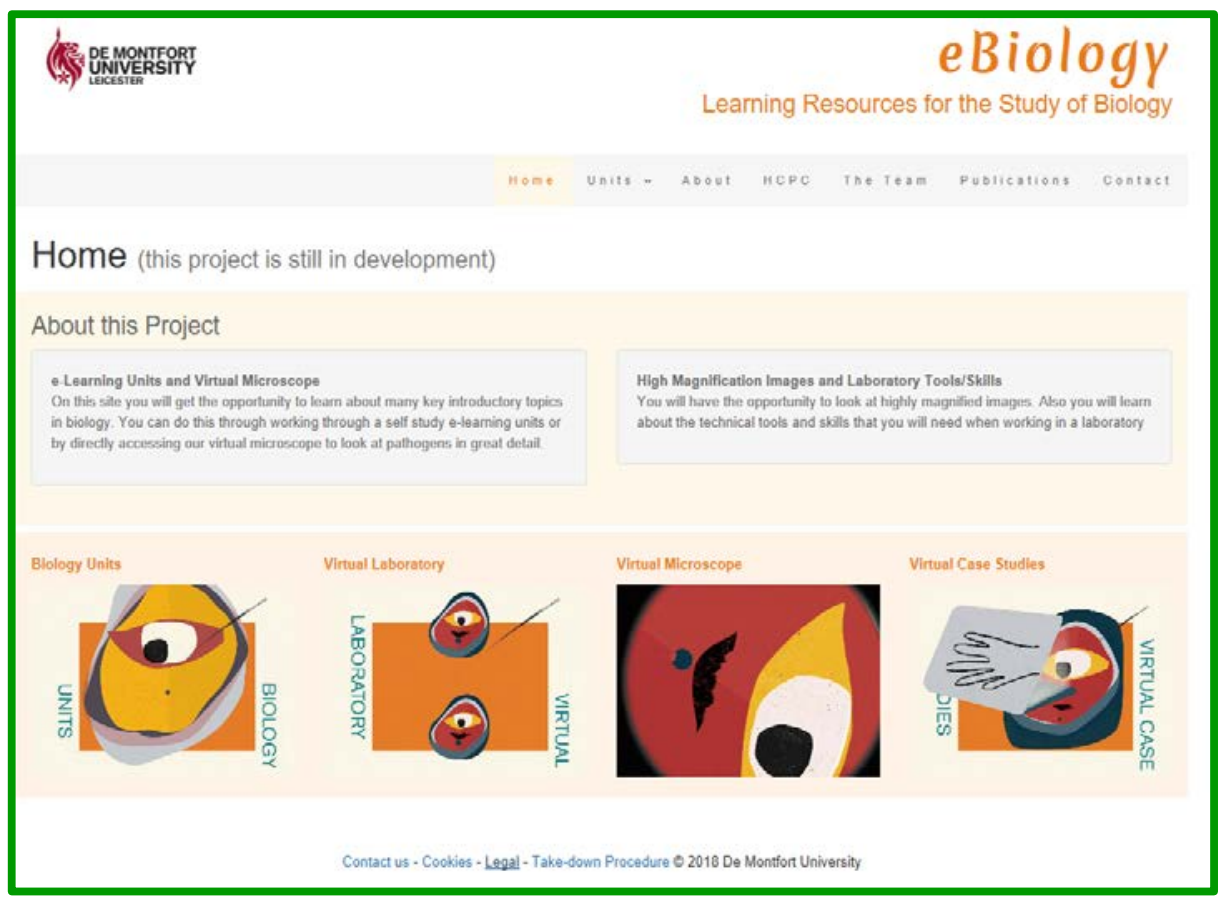

Figure 2. Overview of the DMU e-Biology (under development) showing the future four sections or modules (Image courtesy of DMU; Peña-Fernández A. [6]) http://parasitology.dmu.ac.uk/ebiology/index.htm

\section{DMU VIRTUAL MICROSCOPE MODULES}

Both DMU web-based packages will include a virtual microscope (VM) with a complete library of digitised tissue and clinical slides and cell culture slides/mini-videos, which will have myriad of applicability to enhance and consolidate the learning experience, applicable to any health science undergraduate and postgraduate students.

\subsection{Virtual microscope section in DMU e-Parasitology}

The DMU e-Parasitology's VM is almost completed, an initial description has been included in PeñaFernández et al. (2018) [1]. Briefly, the VM presents a section for each of the three major groups of human-pathogenic parasites: a) protozoa, such as Dientamoeba fragilis and Plasmodium spp.; b) helminths, which covers the three major groups, i.e. trematodes (e.g. Schistosoma spp. eggs), cestodes (e.g. Taenia sp. eggs) and nematodes (e.g. Ascaris lumbricoides eggs or worms of Strongyloides stercoralis); and a future sub-section to collect arthropods affecting humans. The VM not only presents digitised slides from light microscopy but also from fluoresce microscopy to support the learning of novel biochemical techniques for parasitic identification, such as the use of polyclonal antibodies to detect Acanthamoeba trophozoites (images provided by the Cell Culture Laboratory at USP-CEU, Fig. 3). Finally, the VM section is provided with sub-sections for the study of fungi (e.g. microsporidia), macroscopic parasites structures such as Taenia sp. segments and artefacts usually found in parasitological preparations for microscopic analysis (e.g. plantae) 


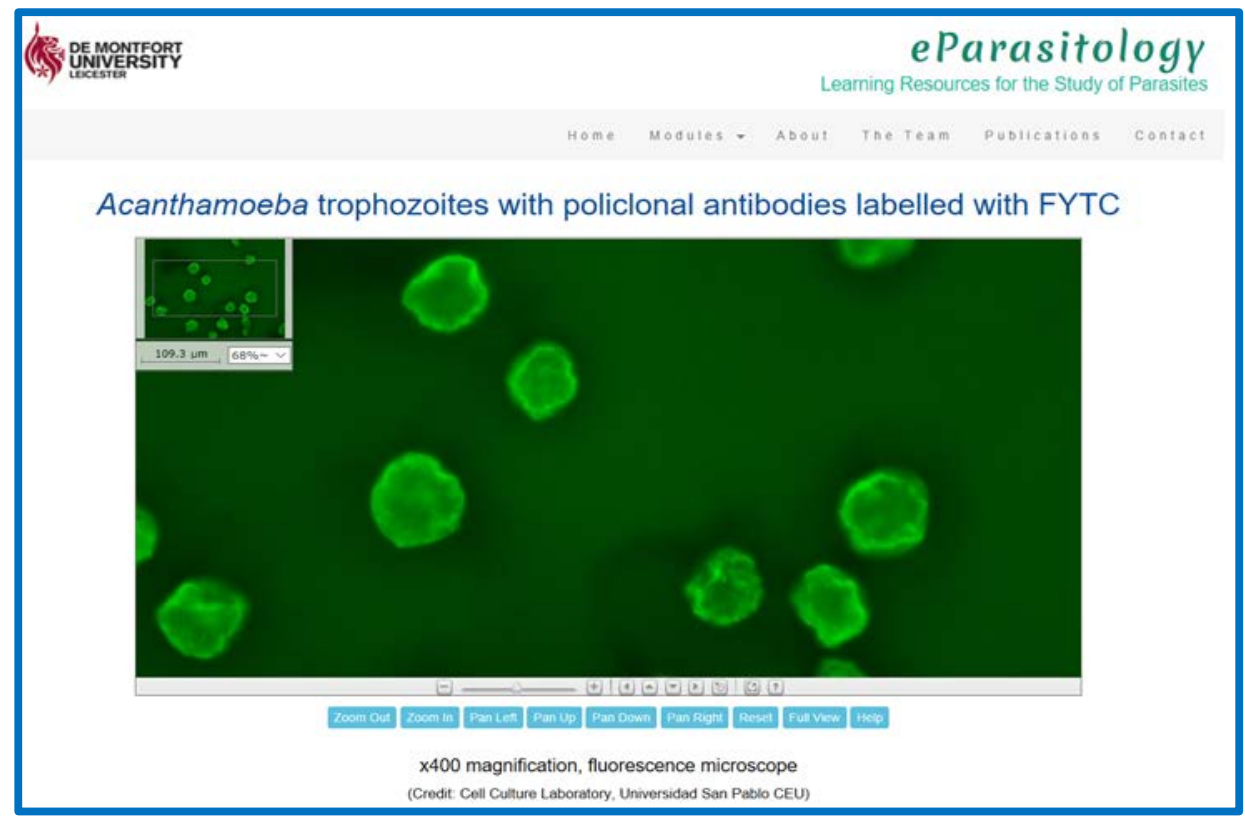

Figure 3. Overview of the virtual slide for Acanthamoeba trophozoites (Image courtesy of Cell Culture Laboratory, USP-CEU, Spain available at the DMU e-Parasitology website

\subsection{Virtual microscope section in DMU e-Biology}

The development of the VM in DMU e-Biology has recently started, the team is following the methods and tools used in the creation of the VM for the study of parasitology, which are briefly explained below. Thus, the new VM will present the following subsections:

- 2D virtual sub-section (Fig. 4). Histological tissue samples for the different subsections studied in the theoretical module of this package, previously named above. To create digitized or virtual slides, real histological slides will be appropriately scanned and photographed (at x40 magnification objective) and then digitised to generate a high magnification digital image of the entire glass slide. The applicability of the microscope is provided to each virtual slide by the gadget Zoomofy®, so the user will be able to zoom in and out of each slide and move around throughout the complete slide, which will facilitate the study of different characteristics for histological study and also to consolidate the learning of the different staining techniques used in a histological laboratory for medical diagnosis.

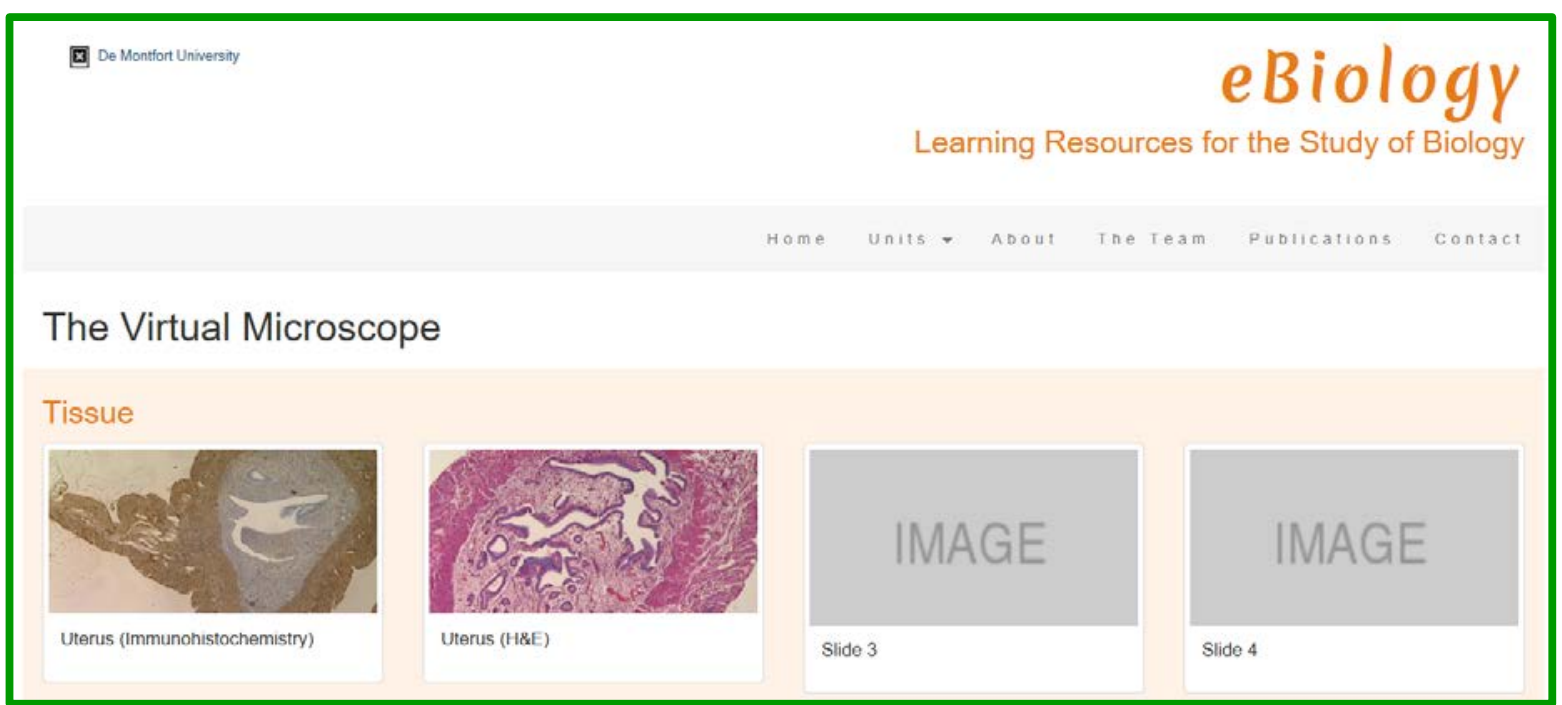

Figure 4. Overview of the DMU e-Biology's Virtual Microscope module displaying the 2D slide sub-section (Image courtesy of DMU; Peña-Fernández A. [6]) http://parasitology.dmu.ac.uk/ebiology/biologyMicroscope.html 
- 3D virtual sub-section. To provide the user with information about the spatial arrangement and morphologies of cells that are essential for life, we are in the process of capturing microscopic photographs/short videos of cells using the novel 3D Cell Explorer microscope kindly on loan from Nanolive (Lausanne, Switzerland) for 6 months (Fig. 5). To our knowledge, DMU is the first UK University to employ 3D super-resolution microscopy of this kind in its taught undergraduate programmes.

\section{And the winner is....}

... De Montfort University in Leicester for their BSc Biomedical Science (BMS) undergraduate course! Congratulations for winning a free 3D Cell Explorer from October to April for undergraduate teaching!

The competition jury was impressed by the BMS's motivation to work with live cell imaging microscopy. Their current aim is to modernise taught practical classes. They are keen to fully promote modern and cutting edge teaching methodologies and have been recently awarded the Teaching Educational Framework Gold award.

De Montfort University is planning to exploit the power of the 30 Cell Explorer microscope to observe live cell processes such as muscle contraction and autophagic cell death, and pathogens.

We are wishing the Biomedical Sciences course all the best with the 30 Cell Explorer and new insights to live cell imaging.

Figure 5. Nanolive website's detail showing the winner of a 6-months loan of the 3D Cell Explorer. More information is available at https://nanolive.ch/higher-education/

\subsection{Development of 3D sub-section in the DMU's Virtual microscopes}

The development of the 3D section in the DMU e-Biology VM is under development. A DMU 'sandwich placement' graphic designer, Maksymilian Szyrmulewicz, is helping us to appropriately develop this section using the applicability of Zoomofy ${ }^{\circledR}$ and the specific 3D Cell Explorer software counterpart, named STEVE, which is able to process high-resolution images of each plane in the sample captured by the 3D microscope hardware, to generate a multiple-viewpoint-holographic image (96 z-stacks cell image).

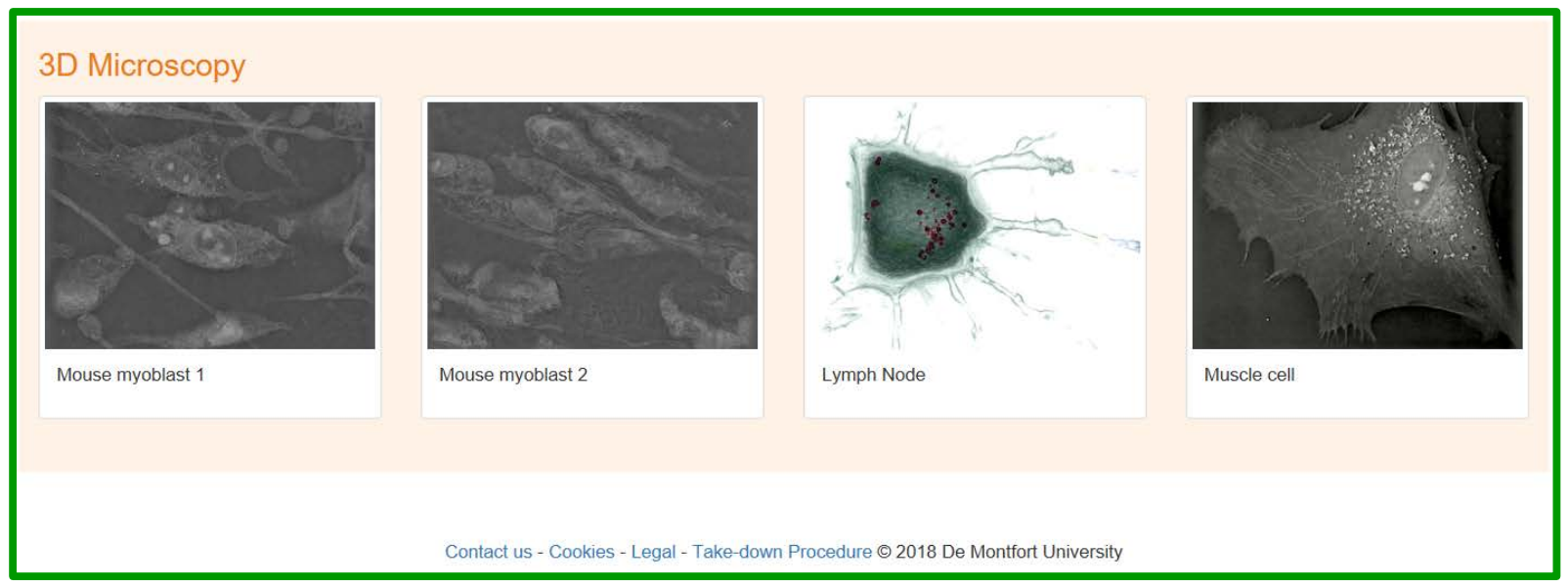

Figure 6. Overview of the DMU e-Biology's Virtual Microscope module displaying the 3D slide sub-section (Image courtesy of DMU; Peña-Fernández A. [6]; myoblast photos courtesy of Dr Young, DMU e-Biology team; the lymph node and muscle cell videos were provided by Nanolive SA, available at https://www.youtube.com/playlist?list=PL4MJjc7DP3VapP44NvB50KHThdsR3gTPK)

In a similar manner as for the $2 \mathrm{D}$ virtual slides, $3 \mathrm{D}$ images will be also provided with the relevant information for the user to facilitate their understanding. So far, two images of muscle STEM cells (mouse's myoblasts) on a collagen bed have been uploaded to this novel sub-section in the DMU eBiology's VM (Fig. 7). Looped animations of serial z-stack images were used to create 3D views of cells in Image J software [13]. 


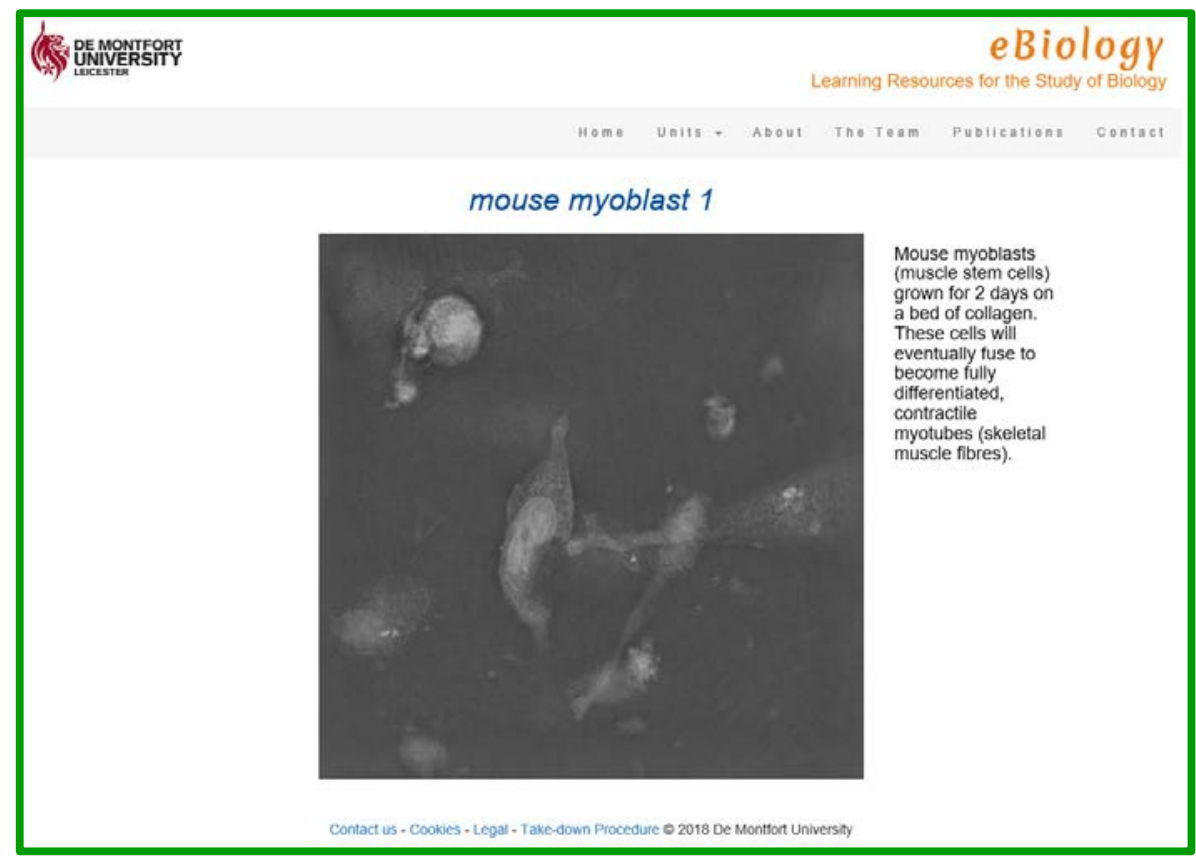

Figure 7. Overview of a 3D z-stack slide in the DMU e-Biology's Virtual Microscope (Myoblast 3D projection courtesy of Dr Young, DMU e-Biology team; http://parasitology.dmu.ac.uk/ebiology/3D/mouse_myoblast_1.htm)

\subsection{A potential 3D sub-section in the DMU e-Parasitology?}

The DMU e-Parasitology team is exploring the possibility of creating 3D images of human parasites with the resources that we have, as DMU does not have a human parasite culture unit. Several attempts with stained glass-slides of animal faecal samples with identified structures of Cryptosporidium spp. and related human microsporidia with the 3D Cell Explorer would have been shown not to be very effective for parasitic diagnostic due to the difficulty of differentiating the tiny parasites (less than $5 \mu \mathrm{m}$ ) from the rest of the sample (already stained faecal matter).

Thus, in the following weeks our team will analyse only fixed in methanol well-slides prepared with cultures of the following parasites at the Cell Culture Laboratory (USP-CEU, Spain):

1 Acanthamoeba spp. (trophozoites and cysts).

2 Spores of microsporidia (not extruded and extruded for the visualization of the polar filament).

3 Leishmania promastigotes.

\section{CONCLUSIONS}

In our opinion, both VMs and their virtual collection of digitised slides, images and short videos make the DMU e-Parasitology and DMU e-Biology unique and different to similar web-based packages as the users will be provided with all the necessary elements to receive a complete learning experience to study human biology and parasitology. Moreover, the collection of virtual slides could serve as a high quality and reliable global image bank of parasites useful for technicians and parasitologists in health centres as well as for the study of cells and tissues. Finally, the study of $3 \mathrm{D}$ images would have a significant potential to enhance the students' learning experience, ensuring our programmes our research-informed and students have access to, and experience of the most cutting-edge developments in the field of biomedical sciences.

\section{ACKNOWLEDGEMENTS}

The authors would like to express their sincere appreciation to the USP-CEU Parasitology laboratory (Madrid, Spain), the Parasitology department at Universidad Miguel Hernández (Elche, Spain) and to Richard Halliwell (NHS, Leicester, UK) for providing high-quality images of parasites in different clinical and culture samples. We would also like to thank to Maksymilian Szyrmulewicz (DMU) for his work to 
develop the VMs. Finally, we thank Kulsum Farshori, Nanolive SA (Lausanne, Switzerland) for the provision and support of the 3D Cell Explorer system, the DMU Research and Innovation project grant to Dr Chris Young, and the DMU Teaching Innovation Project grant to Dr. Peña-Fernández for providing financial support.

\section{REFERENCES}

[1] Peña-Fernández A., Fenoy S., Halliwell R., Izquierdo F., Magnet A., Hurtado C., Bornay F., Acosta L., Ollero MD., Armstrong M., Evans MD., Del Águila C. Development of a virtual library of clinical samples for medical parasitology diagnosis. INTED2018 Proceedings 2018a; pp. 7599-7604.

[2] Ahmed L, Seal LH, Ainley C, De la Salle B, Brereton M, Hyde K, Burthem J, Gilmore WS. WebBased Virtual Microscopy of Digitized Blood Slides for Malaria Diagnosis: An Effective Tool for Skills Assessment in Different Countries and Environments. J Med Internet Res 2016; 18(8): e213.

[3] Čapo I., Bojana AV., Dejan M., Milan P., Jelena IS., Jelena A., Aleksandra FL., Matilda Đ., Dušan L. Virtual Microscopy in Histology and Pathology Education at the Faculty of Medicine, University of Novi Sad. Medical Review 2017; 70(11/12):371-76.

[4] Peña-Fernández A. DMU e-Parasitology. Available at: http://parasitology.dmu.ac.uk/ [accessed 20/01/2019]

[5] Peña-Fernández A., Ollero MD., Fenoy S., Magnet A., Izquierdo F., Peña MÁ., Bornay F., Acosta L., Parker LA., Sgamma T., Del Águila C. Creating a model module for the novel resource DMU eParasitology. ICERI2017 Proceedings 2017a; 1599-1604. ISBN: 978-84-697-6957-7.

[6] Peña-Fernández A., Fenoy S., Evans MD., Sgamma T., Hurtado C., Izquierdo F., Randles M., Young C., Acosta L., del Aguila C. Development of a virtual environment for teaching and learning biomedical techniques and equipment for the study of human pathogens. EDULEARN18 Proceedings 2018b; pp. 7249-7253.

[7] Peña-Fernández A., Magnet A., Peña MA. Focus group to create a virtual case study model unit for the DMU e-Parasitology. EDULEARN18 Proceedings 2018c; pp. 7104-7108. ISBN: 978-84-0902709-5.

[8] Peña-Fernández A., Peña MA., Potiwat N., Coope J., Magnet A. Virtual case studies in the novel resource DMU e-Parasitology. INTED2018 Proceedings 2018d; pp. 6201-6206. ISBN 978-84-6979480-7.

[9] AQA. AS and A-level Biology Specifications. Available at: http://www.aqa.org.uk/subjects/science/as-and-a-level/biology-7401-7402 [accessed 21/01/2019]

[10] Peña-Fernández A. DMU e-Biology. Available at: http://parasitology.dmu.ac.uk/ebiology/index.htm [accessed 20/01/2019]

[11] Peña-Fernández A., Sgamma T., Young C., Randles MJ., Del Águila C., Hurtado C., Evans MD., Potiwat N., Izquierdo F., Peña MA., Coope J., Armstrong M., Bhambra A. Building a DMU e-Biology resource for health sciences' students. ICERI2017 Proceedings 2017b; 1582-1587. ISBN: 978-84697-6957-7.

[12] Peña-Fernández A., Ramos I., Young C., Gray D., Evans MD., Randles M., Zhu L., Lobo-Bedmar MC. Histology resources for promoting blended learning. ICERI2018 Proceedings 2018e; 52185222. ISBN: 978-84-09-05948-5.

[13] Schindelin J.; Arganda-Carreras I., \& Frise E. et al. Fiji: an open-source platform for biological-image analysis. Nature Methods 2012 9(7): 676-682, PMID 22743772, doi:10.1038/nmeth.2019 